\title{
Experiences of the COVID-19 infected persons during isolation in Nepal
}

\section{Sudha Ghimirel*; Govinda Prasad Devkota²; Madhavi Ghimire Gautam²; Sushil Sharma3; Bhagawati Sharma4; Belpatra Nath Yogi5; Prayag Raj Joshi6; Khem Kumar Bhurtel ${ }^{2}$; Anil Kumar Mandal ${ }^{7}$}

${ }^{1}$ Gorkha Campus Gorkha, Gorkha, Tribhuvan University

${ }^{2}$ Mahendra Ratna Campus, Tahachal, Kathmandu, Tribhuvan University

${ }^{3}$ Prithivi Narayan Campus, Pokhara, Tribhuvan University

${ }^{4}$ Mahendra Multiple Campus, Nepalganj, Tribhuvan University

${ }^{5}$ Surkhet Campus, Surkhet, Tribhuvan University

${ }^{6}$ Kailali Multiple Campus, Dhangadi, Midwestern University

${ }^{7}$ SSMYM, Campus, Siraha, Tribhuvan University

*Correspondence: sudha.ghimire42@gmail.com, sudha.ghimire@gc.tu.edu.np;

ORCID: 0000-0003-2041-5724.

\begin{abstract}
Isolation is the separation and restriction of movement of people diagnosed with COVID-19 positive. Isolation is one of the best measures for preventing and controlling pandemics; however, it might be stressful. This study intends to explore the perceptions of COVID-19 infected people towards the COVID-19 pandemic and their experiences at Nepal's isolation centers with the broad theoretical frame of the transactional theory of stress and coping by Lazarus \& Folkman (1986). This qualitative study was conducted in institutional isolation centers in Nepal's Morang, Rautahat, Sindhupalchowk, Tanahun, Banke, Surkhet, and Kailali districts. Thirtyfive participants, five from every seven provinces, were selected using a purposiveconvenient sampling method. Data were collected through interviews in the period of October to December 2020. The findings of the study have been presented in four different themes: personal and environmental attributes, perception of COVID-19 as a stressor, short-term outcome based on situation, and adoption of coping mechanism. There were individual differences in perceiving the COVID-19 as a stressor. Environment and available facilities acted as another source of stress. Similarly, anxiety, irritation, lack of sleep, loss of appetite resulted from stress while staying in isolation. Regarding the coping mechanism of the stress, most participants were found to use mobile phones, play games, watch movies, and talk to family members. We recommend emphasizing psychological intervention comprising meditation, outdoor games, yoga, and counseling in institutional isolation based on this study.
\end{abstract}

Keywords: COVID-19, experience, isolation center, intervention, stress

\section{INTRODUCTION}

The global impact of COVID-19 has brought the most significant crisis for this generation, causing an unfortunate effect on health, world economies, societal cohesion, and people's daily 
lives (Gavin, Lyne, \& McNicholas, 2020). When coronavirus disease got outbreak in December 2019 , many countries' people went for social distancing, quarantine, and isolation to break the transmission chain of the infection. The Cochrane Library evaluating 29 studies indicates that quarantine can reduce the number of infected at rates from $81 \%$ to $44 \%$ and in the number of dead from $61 \%$ to $31 \%$ (Mayr et al., 2020; Panthee, Dhungana, Panthee, Paudel, \& Panthee, 2020). Following the global footpath, Nepal also adopted a mandatory institutional minimum of 14 days quarantine/isolation. For international travelers (air), international travelers (ground), unfeasible home-based quarantine/isolation, and those violating home-based quarantine/isolation as decided by the local authority (Government of Nepal, 2020). Spending time in quarantine/isolation is often an unpleasant and undesirable experience for those who undergo it. It creates separation from loved ones, the loss of freedom, uncertainty over disease status, boredom (Brooks, Webster, Smith, Woodland, \& Rubin, 2020). In this scenario, this study was conducted to explore the experience of the people living in institutional isolation in Nepal using the broad theoretical frame of the transactional theory of stress and coping explained by Lazarus and Folkman (1986).

The transactional theory of stress and coping explains that the same environmental stimulus may cause different reactions for different people depending on how individuals assess and cope with the situation ( Yan, Kim, Zhang, Foo, \& Yanez, 2021). It further explains that stress occurs as a series of the relation between the person, environment, and situation that is highly individualized, situationally specific, and inseparable from the perception of the individual (Lazarus \& Folkman, 1986. Whereas coping is a phenomenon that involves both cognitive and behavioral responses that individuals use to manage internal and/or external stressors perceived (Echemendia, Webbe, Merritt, \& Gonzalez, 2019).

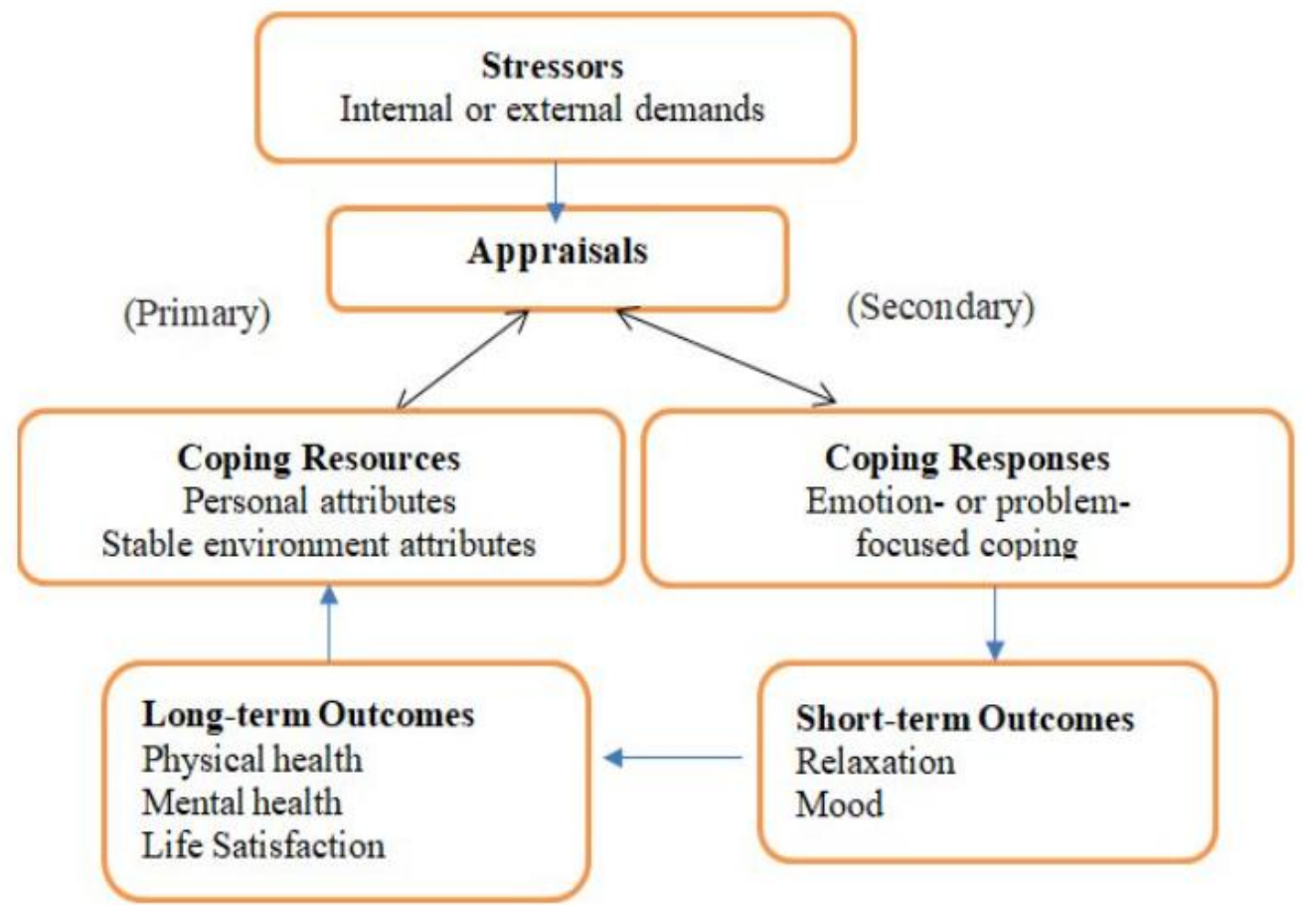

Figure 1. Transactional theory of stress and coping by Lazarus \& Folkman (1986) 
Lazarus and Folkman (1986) identified two cognitive appraisals, which include primary appraisal and secondary appraisal. In primary appraisal, individuals inquire about the particular threatening situation, whereas in the secondary appraisal, individuals question what they can do to respond to the perceived threat. Coping resources include environment and personal attributes, while coping responses are emotionally focused or problem-focused, determining the individual's short-term and long-term outcomes (Margaret, Simon, \& Sabina, 2018). This theory has been widely used in chronic illness, posttraumatic stress disorder, job-related stress and much more. So, we planned to apply the transactional theory of stress and coping in the pandemic situation of COVID-19.

\section{MATERIALS AND METHODS}

\section{Research design}

This study adopts the qualitative method to analyze people's experience living in isolation with a positive COVID-19 report.

\section{Study population and site of study}

Thirty-five participants were purposively selected for study, five from every seven provinces: Morang, Rautahat, Sindhupalchowk, Tanahun, Banke, Surkhet and Kailali districts of Nepal. Due to isolation, prevention of pandemics, and control requirements, interviews with participants were conducted by using mobile phones.

\begin{tabular}{|l|l|l|}
\hline Province & District & Area \\
\hline 1 & Morang & Budhiganga Rural Municipality \\
\hline 2 & Rautahat & Chandrapur Municipality \\
\hline 3 & Sindhupalchowk & Melamchi Municipality \\
\hline 4 & Tanahun & Bandipur Rural Municipality \\
\hline 5 & Banke, & Nepalganj Sub-Metropolitan \\
\hline 6 & Surkhet & Birendranagar Municipality \\
\hline 7 & Kailali & Dhangadhi Sub- Metropolitan \\
\hline
\end{tabular}

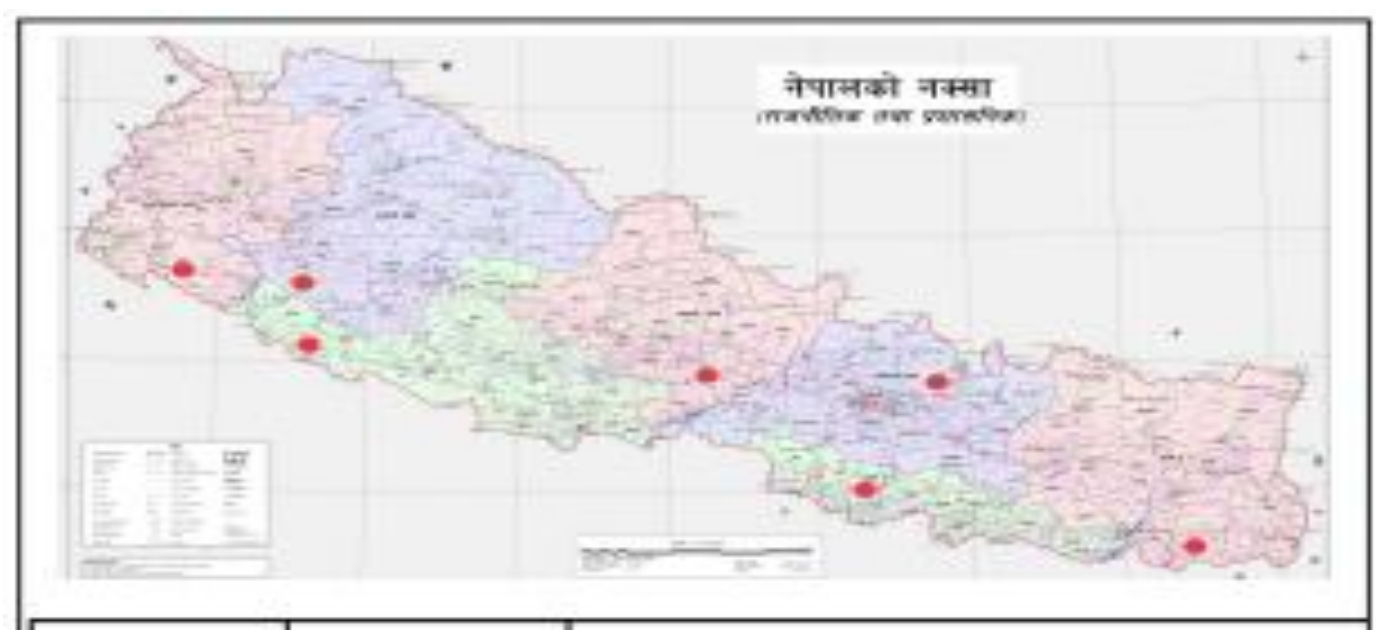

Figure 2. Study site 


\section{Data collection}

First, the list of the community isolation centers was identified from the Ministry of Health (MoHP) along with the responsible body for institutional isolation management. In the second phase, the local government people responsible for institutional isolation management were contacted from the list provided by MoHP. The data were collected from Nepal's Morang, Rautahat, Sindhupalchowk, Tanahun, Banke, Surkhet, and Kailali districts in the timeframe of October to December 2020. Mobile numbers of the people staying in the institutional isolation center were received from the authority, i.e., the isolation manager. Then, telephonic interviews were done with the respondents to collect the required data and information.

\section{Ethical approval}

This study was approved by NHRC (531/2020). Informed consent was taken verbally from the isolation managers and participants before beginning data collection. We have also received verbal consent from the participants to use their quotes to publish as the report.

\section{Inclusion criteria}

The study had followed the inclusion criteria for study participants. The clients should be COVID-19 positive case, clients having mobile phones, living in institutional isolation for a minimum of three days and were willing to participate in the study.

\section{Data collection tool}

Relevant literature and expert opinions were used to design interview guidelines. A mock interview was carried out with two clients to finalize the outline of the interview guideline. The main interview questions were: how they felt during isolation; what the primary form of stress was felt; what kinds of facilities were there; how the illness affected them and how they responded; what they felt and thought about illness; how they coped with the situation.

\section{Data analysis}

The interview was recorded using mobile phones, and the recorded interview was transcribed into English. The data were analyzed manually using the following six steps suggested by Braun \& Clarke (2006); reading all interview materials to form a general understanding of the research object; extracting statements related to the research problem and generating initial code encoding the extracted data and searched for the theme; reviewing the theme; defining and naming the theme and using that produced theme in writing the report. Two researchers independently coded, summarized, and refined the interview materials to form themes.

\section{RESULTS}

\section{Characteristics of the respondents}

A total of 35 interviews using a mobile phone were conducted in seven institutional isolation centers in Nepal. The study cohort included 26 male and nine female COVID-19 infected persons aged 21-47 years. Most of the respondents were married and educated above SLC. Out of 35 COVID-19 infected persons living in institutional isolation centers in different parts of Nepal, 34\% of them have had COVID-19 related symptoms. The rest showed no symptoms of COVID-19. Symptoms comprised headache, fever, cough, throat pain, irritation, loss of appetite, smell, taste, and restlessness, but no life-threatening and critical cases. 


\section{Personal and environmental attributes}

Institutional isolation facilities have been arranged at schools, campuses, hostels, hotels, and other accommodating facilities with local government coordination, and isolation facilities have been organized by the provincial governments and various public and private hospitals across the country. There was a mixed response from the participants regarding the facilities they were provided. Some participants were satisfied with the facilities, whereas some were not. Those who were satisfied with the facilities were most positive towards the situation compared to those who were not. Participants indicated that well-functioning toilets, good food, internet access, medical supervision, TV, games, etc., are essential facilities to be ensured in isolation.

"Well, there is no separate toilet for each person. Two or more infected persons should use a single toilet. The toilet has soap but not enough water. However, women were provided with sanitary pads for menstruation management. We were given two pieces of panties and pads on the first day of hygiene kit distribution. I am happy with the service that was provided" (40-year-old, female, Province B)

Adding the above response, another participant shared:

"Food in the isolation center is well-arranged, but I don't have a good appetite. There is open space outside but no practice of playing games, dancing, exercising, etc. Furthermore, there is no internet facility, so we opened data to run the internet on a mobile phone. No facility to watch television and a counseling service. Such a thing made us more stressed, as we don't have anything to divert ourselves except talking with either a family member or with friends from isolation." (32-year-old male, Provence A).

The study found that physical facilities and entertainment sources significantly decrease stress while staying in an isolation center. The stress is related to both personal exceptions and available facilities as the environment.

\section{Perception COVID-19 as a stressor}

All the respondents agreed that COVID-19 is a new disease, so they were uncertain about its outcome. All respondents expressed, to some extent, fear regarding the disease. Some participants were positive towards the disease and perceived it as normal flu. However, the clients having symptoms were found to be more worried compared to no symptoms. Respondents without having symptoms were also more concerned that they might get worse symptoms after the isolation period.

"This COVID- 19 is a new disease; even scientists and doctors do not know the exact information, symptoms, treatment, and complication of the disease. I am much worried regarding its future health impact. I am not feeling any difficulty now, but can't say what will happen to me in the future. I am very worried about that. Although it looks normal in the beginning, the complexity of this pandemic is terrifying." (38-year-old male, Province D)

Furthermore, there were varied perceptions of COVID-19, especially its origin, survival, sign and symptoms, and prevention and control of the disease. Participants reported different meat items as sources of COVID-19 infection and suggested avoiding consumption of raw meat items to prevent COVID-19. The majority of respondents opined that the virus dies in hot 
temperatures, so they preferred to take hot water to get rid of the infection. They further assumed that washing hands with hot water and soap is better for preventing disease than cold water.

Participant in the interview pinioned:

"The COVID-19 is a pandemic caused by the severe acute respiratory syndrome. This is a dangerous disease. It can even take a life. I came to this isolation ward after I got my positive PCR report. I had heard several news reports of Italy about coronavirus cases, so I was scared to listen to my positive report for the first time. I thought I would die. I became despondent. But now I am feeling better" (34-year-old male, Province E).

The majority of the respondents shared that disease transmits through the droplet, so they need to have physical distance and use a mask to prevent disease transmission. Furthermore, some participants were worried about the social stigma that might be faced after COVID-19.

"I haven't told my family that I am COVID- 19 positive. They might be worried. My home is a remote place in Nepal. People see COVID-19 disease negatively. They might stop keeping relations with my family. So, I am not sharing my report with them" (26 year-old male, Provence B)

The study showed that participants had a general knowledge of the introduction, causes, signs and symptoms, and preventive measures of COVID-19. Furthermore, the same diseases and situation is perceived differently by participants.

\section{Coping responses and short-term outcomes}

The participants perceived numerous stress due to having COVID positive and living in an isolated center far from family and relatives. In addition, the viral nature of the disease, personal life and social changes as a result of isolation, and concerns regarding the health of family members made them increase anxiety. The majority of the participants reported discomfort caused by the symptoms of COVID-19. They feared death and were concerned about their prognosis future. Similarly, the majority of participants felt stressed separating from their family and felt socially distracted and life threatened. They were also bored and felt alone, having limited personal liberty in quarantine centers.

"I feel chest pain, difficulty breathing, and coughing that makes me uncomfortable, and I feel weak after abatement of the fever." (30-year-old female, Province B).

Another participant shared:

"When I am alone, I feel I may die, and if I do not die, in the future I will have other lasting effects because of COVID-19 because its new disease, which makes me uncomfortable." (45-year-old male, Province D).

Similarly, some participants were more worried about their family members. As it's a communicable disease and their family member might have infected them. They were more anxious because they hadn't seen them for a long time (staying in isolation).

"Due to close contact with me, my family members might also get this virus from me. When I think about my family, I get more stressed. Maybe I am much worried about my 
family. I don't get enough sleep and even if I fall asleep for a while, I wake up." (26 year-old male, Province G).

On the other hand, some participants shared that they felt stressed about the social stigma arising from COVID-19, while others felt lonely and alone.

"I am not interested in talking with anyone. I feel very lonely. I lie in bed and stare at the ceiling. The room is so quiet that I can only hear the sound of the scream." (34-yearold male, Province F).

During the interview, triggering psychological distress was recorded, most notably the viral nature of the disease, life, and social changes resulting from isolation. Concerns regarding the health of family members were short-term outcomes of the disease.

\section{Adoption of coping mechanism}

All the participants adopted psychological defense mechanisms to cope with their stress, by distraction, self-consciousness, humor, games, sharing a feeling, etc. Mobile phones/ internet was a highly used device to engage in. It distracted them from the situation they were undergoing. Most of the participants talked with fellow clients and shared their feelings to cope with the situation.

"I feel like I am not a single who is having this problem. We all from this hall are going through the same situation. So, we talk and share our things. But we always maintain social distance. Talking with others feels good, and we forget our pain for a while. In the evening, we also go to the roof-top and participate in group dance and exercise." (37-year-old male, Province $G$ ).

Furthermore, some were found to have breathing relaxation, mindfulness, music meditation. At the same time, some respondents reported taking naps to get rid of stress.

\section{DISCUSSION}

This study was conducted to explore the people's reported positive experiences with COVID-19 and remained in institutional isolation centers in seven provinces of Nepal with the broad theoretical frame of the transactional theory of stress and coping by Lazarus \& Folkman (1986). The findings of the study were presented in four different themes based on theory: personal and environmental attributes, perception of COVID-19 as a stressor, short-term outcome based on situation, and adoption of coping mechanism. All the theoretical components can't be explained in this study because this study is one point qualitative research, where we had interaction with study participants for a single time for a short duration. The long-term outcomes and coping strategies that individuals adopt can't be studied in a single time frame. Thus, this theory is partially applicable in this study.

A study conducted among caregivers of dementia from Virginia showed that caregivers had considered stressors related to COVID-19 as a primary appraisal and available support, resources as a secondary appraisal. Similarly, caregivers who were more concerned about the COVID-19 pandemic had experienced more stress compared to those who had recognized positive aspects of the pandemic (Savla, Roberto, Blieszner, McCann, \& Knight 2021). The finding of this study supports the finding of our study; despite being COVID- 19 positive, participants perceived disease differently; some of them had perceived it as a fatal disease, whereas some had perceived it as simple seasonal flu. Similarly, a qualitative study conducted 
to investigate increased stressful life events (SLEs) due to COVID-19 pandemic in the U.S.A. based on Lazarus and Folkman's transactional model, participants varied in perceived threat and challenge appraisals of COVID-19, indicating both calm and fear. Among participants, the majority (95\%) were predominantly negative; $42 \%$ very negative, and nearly half $(53 \%)$ were moderately negative (Jean-Baptiste, Herring, Beeson, Dos Santos, \& Banta, 2020). Similarly, a web-based questionnaire focused on the COVID-19 pandemic was completed by 1,272 people from May 4 to May 17, 2020, based on the transactional model of stress and coping, found that people reported difficulties across eight domains: social relationships, activity restrictions, psychological, health, financial, global environment, death after the COVID-pandemic. This finding is similar to the finding of our study, where participants were more concerned about lifestyle after COVID-19 and its uncertain outcomes.

Furthermore, despite the lack of social interaction, isolation, and loss of income, the uncertainty of the disease was the triggering factor for stress observed in our study. Our research findings are in line with the study conducted with people living in quarantine from China, where most of the participants felt exhausted and socially excluded because of COVID-19 (Sun et al., 2020). In contrast, a poor attitude towards quarantine, boredom and poor coping mechanisms, fears of infection and stigma, difficulties in access to health care, and unnecessary post-quarantine follow-ups were reported as stressful for participants from Uganda (Ndejjo, Naggayi, Tibiita, Mugahi, \& Kabira, 2021). Nepal government had developed COVID-19 isolation management guideline 2077, where the facilities required to run the intuitional isolation were mentioned. The isolation centers this study had conducted had basic facilities complying with the guideline 2077; a single bed with a physical distance of two meters and drinking water facilities. However, in some centers, water quality was reported poor. They were provided with a four times meal in a day, hygiene kit, hand washing, and toilet facilities. Health workers were also available to monitor the health condition of clients. This indicates that the isolation centers were well facilitated and convenient to live in. However, some centers didn't have internet, CCTV, and TV. According to the guideline, these are the additional facilities and had not obligated in isolation centers. A study based on Lazarus \& Folkman (1986) highlights that the environment can act as a major stressor. The finding supports our study, where participants who were staying in enough facilities at isolation perceived less stress than staying in fewer facilities. The study by Sun, Wei, Wang, Wang, \& Shi (2020) among Nurses working for COVID-19 positive had adopted speculation, distraction, self-consciousness, humor, rationalization as a psychological defense mechanism to cope with stress. In contrast, in our study, participants were found to be playing games, using mobile to keep in touch with others and activating the social network, watching movies as a distraction to get free from stress as coping of the situation.

\section{CONCLUSION}

Patients with COVID-19 who were in an isolation center were in a state of mental stress, and transactional theory of stress and coping effectively explained the situation. Our study recommends that while running insolation centers, we need to prioritize both the personal feeling of people and environmental conditions as both of them are equally responsible for triggering the stress.

\section{Ethics approval}

The ethical approval for this study was obtained from Nepal Health Research Council (531/2020) 


\section{Consent for publication}

Consent for publication was received from research participants and approval from the isolation manager.

\section{Availability of data and materials}

The datasets used in this study are available with the corresponding author and can obtain on reasonable request. If needed, the authors are happy to share the raw data.

\section{Competing interests}

The authors declare that they have no competing interests.

\section{Acknowledgments}

The authors acknowledge the HEAN (Health Education Association of Nepal) for logistic support for conducting this study.

\section{REFERENCES}

Braun, V. \& Clarke, V. (2006). Using thematic analysis in psychology. Qualitative Research in Psychology, 3(2), 77-101. Doi:10.1191/1478088706qp063oa

Brooks, S. K., Webster, R. K., Smith, L. E., Woodland, L., \& Rubin, G. J. (2020). The psychological impact of quarantine and how to reduce it: Rapid review of the evidence. The Lancet, 395(10227): 912-920. Doi:10.1016/ S0140-6736(20)30460-8

Echemendia, R. J., Webbe, F. M., Merritt, V. C., \& Gonzalez, G. (2019). Assessment in sports: Psychological and neuropsychological approaches. In G. Goldstein, D. N. Allen, \& J. DeLuca (Eds.), Handbook of Psychological Assessment (Fourth Edition): 275-304. https://doi.org/10.1016/B978-0-12-802203-0.00009-2

Gavin, B., Lyne, J., \& McNicholas, F. (2020). Mental health and the COVID-19 pandemic. Irish Journal of Psychological Medicine, 37(3): 156-158. Doi:10.1017/ipm.2020.72

Government of Nepal, MoHP. (2020). Health Sector Emergency Response Plan, COVID19Pandemic. Retrieved from https://www.who.int/docs/default-source/nepaldocuments/novel-coronavirus/health-sector-emergency-response-plan-covid-19endorsed-may-2020.pdf?sfvrsn=ef831f44_2

Jean-Baptiste, C. O., Herring, R. P., Beeson, W. L., Dos Santos, H., \& Banta, J. E. (2020). Stressful life events and social capital during the early phase of COVID-19 in the U.S. Social Sciences \& Humanities Open, 2(1): 100057. doi: 10.1016/j.ssaho.2020.100057

Lazarus, R. S., \& Folkman, S. (1986). Reply to Deutsch and Green. American Psychologist, 41(6): 715-716. doi: 10.1037//0003-066x.41.6.715

Margaret, K., Simon, N., \& Sabina, M. (2018). Sources of Occupational Stress and Coping Strategies among Teachers in Borstal Institutions in Kenya. Edelweiss Psychiatry Open Access, 2(1): 18-21. Doi: 10.33805/2638-8073.111

Mayr, V., Ai, D., Chapman, A., Persad, E., Klerings, I., Wagner, G., ... Zachariah, C. (2020). Quarantine and COVID-19: a rapid review. https://doi.org/10.1002/14651858.CD013574.www.cochranelibrary.com 
Nussbaumer-Streit, B., Mayr, V., Dobrescu, A. L., Chapman, A., \& Gartlehner G. (2020). Quarantine alone or in combination with other public health measures to control COVID-19: A rapid review. Cochrane Database Syst Rev. 9(9): CD013574. doi: 10.1002/14651858.CD013574.pub2

Ndejjo, R., Naggayi, G., Tibiita, R., Mugahi, R., \& Kabira, S. P. S. (2021). Experiences of Persons in COVID-19 Institutional Quarantine in Uganda: A Qualitative Study. BMC Public Health 21(1):1-11. doi: 10.1186/s12889-021-10519-Z

Panthee, B., Dhungana, S., Panthee, N., Paudel, A., \& Panthee, S. (2020). COVID-19: The current situation in Nepal. New Microbes and New Infections, 37: 100737. Doi: 10.1016/j.nmni.2020.100737

Savla, J., Roberto, K. A., Blieszner, R., McCann, B. R., \& Knight, A. L (2021). Dementia Caregiving during the "Stay-at-Home" Phase of COVID-19 Pandemic. Journals of Gerontology: Psychological Sciences and Social Sciences, 76(4), E241-E245. doi: 10.1093/geronb/gbaa129

Sun, N., Wei, L., Wang, H., Wang, X., \& Shi, S. (2021). Qualitative study of the psychological experience of COVID-19 patients during hospitalization. Journal of affective disorders, 278, 15-22. doi: 10.1016/j.jad.2020.

Yan, J., Kim, S., Zhang, S. X., Foo, M. D., \& Yanez, J. A.(2021). Hospitality workers' COVID19 risk perception and depression: A contingent model based on transactional theory of stress model. International Journal of Hospitality Management, (2): 1-48. Doi: $\underline{10.1016 / j . i j h m .2021 .102935}$ 